\title{
ANL/TD/CP-98463
}

\section{PERFORMANCE LIMITS FOR FUSION FIRST-WALL} STRUCTURAL MATERIALS*

\author{
D.L. Smith, S. Majumdar, M. Billone, and R.F. Mattas \\ Fusion Power Program, Argonne National Laboratory \\ 9700 S. Cass Ave., Argonne, IL 60439, USA

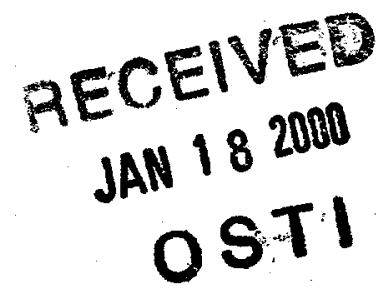 \\ Telephone: ++1 630 252-4837, FAX: ++1 630252 5287, E-mail: dalesmith@anl.gov
}

\section{Introduction}

Key features of fusion energy relate primarily to potential advantages associated with safety and environmental considerations and the near endless supply of fuel. However, it is generally concluded that high performance fusion power systems will be required in order to be economically competitive with other energy options. As in most energy systems, structural materials operating limits pose a primary constraint to the performance of fusion power systems. It is also recognized that for the case of fusion power, the first-wall/blanket system will have a dominant impact on both the economic and safety/environmental attractiveness of fusion energy. The first-wall blanket structure is particularly critical since it must maintain high integrity at relatively high temperatures during exposure to high radiation levels, high surface heat fluxes, and significant primary stresses.

The performance limits of the first-wall/blanket structure will be dependent on the structural material properties, the coolant/breeder system, and the specific design configuration. Key factors associated with high performance structural materials include (1) high temperature operation, (2) a large operating temperature window, and (3) a long operating lifetime. High temperature operation is necessary to provide for high power conversion efficiency. As discussed later, low-pressure coolant systems provide significant advantages. A large operating temperature window is necessary to accommodate high surface heating and high power density. The operating temperature range for the structure must include the temperature gradient through the first wall and the coolant system $\Delta \mathrm{T}$ required for efficient energy conversion. This later requirement is dependent on the coolant/breeder operating temperature limits. A long operating lifetime of the structure is important to improve system availability and to minimize waste disposition. 


\section{DISCLAIMER}

This report was prepared as an account of work sponsored by an agency of the United States Government. Neither the United States Government nor any agency thereof, nor any of their employees, make any warranty, express or implied, or assumes any legal liability or responsibility for the accuracy, completeness, or usefulness of any information, apparatus, product, or process disclosed, or represents that its use would not infringe privately owned rights. Reference herein to any specific commercial product, process, or service by trade name, trademark, manufacturer, or otherwise does not necessarily constitute or imply its endorsement, recommendation, or favoring by the United States Government or any agency thereof. The views and opinions of authors expressed herein do not necessarily state or reflect those of the United States Government or any agency thereof. 


\section{DISCLAIMER}

Portions of this document may be illegible in electronic image products. Images are produced from the best available original document. 
The performance of a fusion first-wall/blanket structure will be limited by both the inherent properties of the candidate structural materials and by factors imposed by the fusion system environment. The physical and neutronic properties of most candidate materials are characteristic of the base alloy system. For example, the thermal conductivity and thermal expansion coefficients of transition metals such as vanadium alloys and ferritic steels are insensitive to composition variations, thermochemical treatment and even irradiation effects. Similarly, the neutronic properties of the base materials cannot be changed except by isotopic tailoring, which is probably not a realistic solution. Notable exceptions include the thermal conductivity of $\mathrm{SiC} / \mathrm{SiC}$ composites which is highly dependent on the microstructure and the thermal and electrical conductivities of high conductivity copper, which are sensitive to minor compositional variations. Fabrication constraints such as welding and joining are important since joints are typically more susceptible to failure than the base material. However, significant modifications to the mechanical properties of most materials can be made by modest variations of composition, microstructure or thermomechanical treatment.

Limits imposed by the fusion system environment include such factors as the hydrogen plasma, the coolant/breeder system, the high-energy neutron environment, and the magnetic field effects. Primary issues related to the hydrogen plasma include hydrogen (DT) interactions involving solubility and permeability, and surface heat flux deposition. Coolant/Breeder compatibility issues include chemical interactions, coolant system pressure, and coolant/breeder temperature constraints. The high-energy neutrons from the plasma produce displacement damage to the structural materials and significant transmutations. In most materials the helium and hydrogen produced by nuclear interactions are the most important; however, transmutations of higher- $\mathrm{Z}$ atoms are important for some materials.

The primary magnetic field effects relate to stresses associated with ferromagnetic materials; e.g., ferritic steels; magnetohydrodynamic interactions of conducting liquid coolants; and stresses associated with currents induced in the structure interacting with the magnetic field, particularly during disruptions.

\section{Candidate First-Wall Structural Materials}

Three classes first-wall materials are listed in Table 1. The primary candidate structural materials for advanced fusion system application are ferritic steels, vanadium alloys and $\mathrm{SiC} / \mathrm{SiC}$ composites $(1,2)$. Copper alloys and austenitic steels are proposed for near-term applications (3). Refractory metal alloys of tungsten, tantalum, niobium and 
molybdenum were considered as possible candidate structural materials in the early stages of the fusion program but were dropped for various reasons. These alloy systems are being re-evaluated with the current emphasis on high performance. The possibility of using free surface liquid walls for high surface heat fluxes has been suggested (4); however, the potential of this approach for first-wall applications in magnetic fusion applications appears to be quite remote. The emphasis of this paper is limited primarily to the three candidate materials proposed for advanced fusion power systems.

\section{Factors affecting structural materials operating limits}

Primary factors affecting the performance limits of the candidate structural materials are discussed in this section. Since space limitations preclude a comprehensive assessment of all issues, this paper attempts to highlight some of the key issues for the various materials options. Table 2 presents a summary of the neutronic responses of the candidate materials. Values given are only approximate since precise values are dependent on the specific design configuration and the combination of materials. Primary observations from this table include (1) the very high $\mathrm{He}$ and $\mathrm{H}$ transmutation rates for the $\mathrm{SiC} / \mathrm{SiC}$ composite, (2) the relatively low $\mathrm{He}$ and $\mathrm{H}$ transmutation and displacement damage rates for the tantalum and tungsten alloys, (3) the very high dose rate and decay heat for tantalum, and (4) the relatively low dose rate and decay heat for the $\mathrm{SiC} / \mathrm{SiC}$ composite and vanadium alloy. Based on these data alone, use of a tantalum alloy appears unacceptable because of dose rate considerations. The lifetime of the $\mathrm{SiC} / \mathrm{SiC}$ composite with the high helium generation rate is a major concern regarding the feasibility of this material. This issue will likely be exacerbated by the high hydrogen transmutation rate and the fact that hydrogen diffusion/permeation in $\mathrm{SiC}$ is very low. The relatively high $\mathrm{He}$ generation rates for all materials compared to that in a fission reactor spectrum represents one of the major lifetime issues for a fusion first-wall system. The high- $\mathrm{Z}$ materials, $\mathrm{Ta}$ and $\mathrm{W}$, exhibit relatively low $\mathrm{He}$ and $\mathrm{H}$ transmutation rates. Of the three primary candidate materials, the vanadium alloys exhibit the lowest $\mathrm{He}$ and $\mathrm{H}$ transmutation rates; however, even for the vanadium alloys the He is expected to impact the operating lifetime.

The inherent physical properties of the structural materials will also influence the performance limits. Table 3 presents the calculated temperature gradient through a characteristic wall for surface heat fluxes of 1 and $2 \mathrm{MW} / \mathrm{m}^{2}$ which correspond approximately to neutron wall loadings of 5 and $10 \mathrm{MW} / \mathrm{m}^{2}$. The wall $\Delta T$ s for the ferritic steel and vanadium alloy are similar, but both materials require a rather wide operating temperature range to accommodate a $2 \mathrm{MW} / \mathrm{m}^{2}$ surface heat flux plus a reasonable 
coolant system $\Delta \mathrm{T}$. The thermal conductivities of these alloys are not significantly affected by irradiation or modest compositional variations. This issue for the $\mathrm{SiC} / \mathrm{SiC}$ composite is much more complex. The thermal conductivity of the $\mathrm{SiC}$ is strongly influenced by the temperature, microstructure, impurity level, and irradiation $(5,6)$. Commercially available $\mathrm{SiC}$ composites exhibit fairly high $(40-60 \mathrm{~W} / \mathrm{m} \cdot \mathrm{k})$ conductivities with the fiber directions. However, the thermal conductivity across the fibers is reduced by a factor of five or more (5). Further reductions by up to factors of five at lower temperature are observed after irradiation. Recent in-reactor measurements on so-called improved $\mathrm{SiC} / \mathrm{SiC}$ composites also exhibit substantial reductions in thermal conductivities to $\sim 10 \mathrm{~W} / \mathrm{m} \cdot \mathrm{k}$ at temperatures of $500^{\circ} \mathrm{C}$ and lower (6). One might expect that the high $\mathrm{He}$ and $\mathrm{H}$ transmutation rates would cause additional reductions in the thermal conductivity. The values shown in Table 3 indicate that the surface heat flux for a $\mathrm{SiC} / \mathrm{SiC}$ first wall would be limited to relatively low values based on the reductions to the thermal conductivity during irradiation and the assumed temperature limits for this material.

A structural materials design criteria for fusion applications has been developed as part of the ITER Engineering Design Activity (7). In certain cases the ITER Structural Design criteria (ISDC) allows higher surface heat flux limits than values based on the simple $3 \mathrm{~S}_{\mathrm{m}}$ design criteria used in the past. A structural design criteria based on the ISDC has been extended to include radiation-induced embrittlement and thermal creep (but not fatigue) for advanced structural alloys, viz., vanadium-base alloys (8). Figure 1 shows the time independent maximum surface heat flux as a function of wall thickness for the $\mathrm{V}-4 \mathrm{Cr}-4 \mathrm{Ti}$ alloy properties. The $3 \mathrm{~S}_{\mathrm{m}}$ limit indicates a maximum surface heat flux of $\sim 1.2 \mathrm{MW} / \mathrm{m}^{2}$ for a wall thickness of 5-6 mm. The new design criteria allows the maximum surface heat flux to be set by the Bree limit for ductile materials $\left(\varepsilon_{u}>2 \%\right)$. For the case of a $750^{\circ} \mathrm{C}$ maximum temperature limit, the allowable surface heat flux is $\sim 2.5 \mathrm{MW} / \mathrm{m}^{2}$ for a $4.2 \mathrm{~mm}$-thick wall. This surface heat flux would correspond to a neutron wall loading of $\sim 10 \mathrm{MW} / \mathrm{m}^{2}$. For the case where the uniform elongation is reduced below $2 \%$, the maximum heat flux is set by the $S_{d}$ limit, which is $\sim 1.8 \mathrm{MW} / \mathrm{m}^{2}$. In either case, substantially higher wall loads are allowable for vanadium alloy with the new criteria compared to the $3 \mathrm{~S}_{\mathrm{m}}$ criteria. Figure 2 shows the uniform elongation of three vanadium alloys in the range of $400-700^{\circ} \mathrm{C}$. Since the values exceed $2 \%$, the Bree limit would apply. The new design criteria has not yet been applied to the ferritic steels, but a similar set of criteria should apply, albeit with a lower $\mathrm{T}_{\max }$. However, since the uniform elongation of irradiated F82H ferritic steel indicated in Fig. 2 is less than $2 \%$, the $S_{d}$ limit would apply. Since a similar design criteria for the $\mathrm{SiC} / \mathrm{SiC}$ composite has not been developed, estimates of the surface heat flux limits cannot be made with any certainty. 
Although this type of design criteria has not yet been applied to tungsten and molybdenum alloys, the relative advantages of these characteristically low ductility materials may be significantly less than previously assumed.

At high temperatures thermal creep will become a factor. Figure 3 shows an example of the primary stress limits for the vanadium alloy. The allowable primary stress at lower temperatures is controlled by the tensile properties. The creep properties become more important as the design lifetime increases. This figure illustrates the significant advantages of low-pressure coolants since coolant pressure is the dominant contributor to the primary stress. For example, the maximum temperature for a primary stress of 120 $\mathrm{MPa}$ is $\sim 650^{\circ} \mathrm{C}$, whereas the maximum temperature for a primary stress of $40 \mathrm{MPa}$, which is typical of a lithium cooled system, is $\sim 750^{\circ} \mathrm{C}$.

Similar type behavior is derived for the ferritic steels. Figure 4 is a temperature/neutron fluence map for the F82H ferritic steel with water coolant presented by Hishinuma etal (10). At temperatures above $\sim 450^{\circ} \mathrm{C}$ this steel exhibits a reduction of yield strength or softening with neutron damage. The reduction in allowable temperature is also indicated for creep strains of 1 and $2 \%$. The lower temperature limit is affected by the ductilebrille-transition (DBTT). This figure projects a significant increase in the DBTT; however, for both the ferritic steel and the vanadium alloy, the effects of $\mathrm{He}$ on the mechanical properties are highly uncertain. The shift in the DBTT may in fact be significantly greater than indicated if the effects of $\mathrm{He}$ and $\mathrm{H}$ transmutations are included. Further research on $\mathrm{He}$ (and $\mathrm{H}$ ) effects on properties of both ferritic steels and vanadium alloys is of critical importance.

Neither the database nor the design criteria for the $\mathrm{SiC} / \mathrm{SiC}$ composite are sufficiently developed to provide a similar assessment of the performance limits of this material. However, key constraints for the $\mathrm{SiC} / \mathrm{SiC}$ appear to be related to substantial reductions in thermal conductivity with irradiation, effects of the high $\mathrm{He}$ and $\mathrm{H}$ transmutation rates on the mechanical integrity and swelling, concerns related to fabrication and hermeticity, and possible tritium retention.

As mentioned previously, the coolant/breeder system will impact the acceptability and performance limits of the candidate materials. It is beyond the scope of this paper to present a comprehensive assessment of all structure/breeder/coolant constraints; however, selected critical issues are presented. Clearly use of water coolant with a lithium breeding material is not acceptable. Compatibility issues associated with hydrogen or tritium are important for several systems. Table 4 presents approximate values for the 
tritium pressure resulting from a single pass of the breeder/coolant (He purge in the case of a $\mathrm{Li}$ ceramic breeder) in order to provide adequate breeding. Typically for a selfcooled breeder system, only a few percent of the coolant system will be diverted to the tritium processing system. Therefore, the tritium pressure in the breeder/coolant will approach values one-to-two orders of magnitude higher than those listed in Table 4. Lithium is a special case with an extremely low tritium partial pressure, which should not impact any of the candidate structural materials. However, $\mathrm{PbLi}$ and Flibe (assuming $\mathrm{T}$ is not the reduced form) will exhibit tritium pressures that may lead to excessive tritium inventories in $\mathrm{V}, \mathrm{Nb}$ and $\mathrm{SiC} / \mathrm{SiC}$. This does not appear to be a problem for the ferritic steel, Mo or W alloys.

Compatibility limits associated with oxygen impurity in helium coolant are of particular importance for all refractory metals. It is clear that none of these alloys ( $\mathrm{V}, \mathrm{Nb}, \mathrm{Ta}, \mathrm{Mo}$, and $W$ ) can be exposed to air or oxygen at elevated temperatures. However, the oxygen level in He coolant must be maintained at extremely low levels to be acceptable for use with the refractory metals. This issue has been addressed for the Group V metals (V, Nb, $\mathrm{Ta}$ ), but has not been emphasized for Mo and $\mathrm{W}$ alloys. The calculated oxygen concentrations in high pressure (100 atm) He required to avoid oxidation of Mo and W are given in Table 5. The oxidation kinetics of $\mathrm{Mo}$ and $\mathrm{W}$ are also very high and oxides are even volatile at temperatures above $700-800^{\circ} \mathrm{C}$. An extremely leak-tight system is required to maintain oxygen levels in He at acceptable levels even for Mo and W alloys. However, the issue is further complicated by tritium containment considerations. The preferred approach for containing tritium in a high temperature He-cooled system is by oxidizing the tritium to reduce the tritium pressure and, hence, the permeation rates. However, oxidation of tritium will also lead to oxidation of the refractory metals. Adequate control of both oxygen and tritium remains a question for the He-cooled refractory metal systems.

\section{Summary of Structural Material Limits}

Simple compatibility of the temperature limits for the various structural material/coolant systems will affect the performance limits of several systems. Figure 5 gives the estimated operating temperature limits for candidate structural materials and coolant/breeder materials. In most cases these values are not well established and, as stated earlier, depend on design considerations such as coolant pressure, chemical compatibility, and irradiation lifetime. The lighter shaded areas provide some indication of uncertainties and system dependence. The following general conclusions can be drawn. 
Ferritic Steels

- Only ferritic steels may be compatible with water coolant because of low temperature radiation-induced embrittlement. The key issue for ferritic steels relates to the effect of $\mathrm{He}$ and $\mathrm{H}$ transmutations on the low-

temperature embrittlement, which could also preclude their use with water coolant.

- Energy conversion efficiency and wall load limits with He coolant are severely constrained by the upper temperature limits imposed by radiation softening and thermal creep.

- The temperature limits for ferritic steels do not appear to be compatible with the operating temperatures of Flibe imposed by the high melting temperature.

- The current hope for a high performance system is placed on ODS ferritic steels, which are quite different from the conventional ferritic steels. Key issues for the ODS steels relate to fabrication and joining, fracture toughness, and $\mathrm{He} / \mathrm{H}$ embrittlement.

Vanadium alloys

- Use with water cooling is questionable because of low-temperature embrittlement.

- An operating temperature window of $\sim 350^{\circ} \mathrm{C}\left(400-750^{\circ} \mathrm{C}\right)$ at a neutron wall loading of $5-10 \mathrm{MW} / \mathrm{m}^{2}$ and a power conversion efficiency of $\sim 40 \%$ appears feasible with low-pressure Li coolant if a reliable insulator coating can be developed. In addition to the insulator coating requirement, the key issue involves the effects of He transmutation on the performance limits.

- The feasibility of use with He coolant remains a question because of the combination of oxidation and tritium containment. The problem is reduced with a $\mathrm{Li}$ breeder but exacerbated with most other breeder options.

- Use with Flibe is questionable because of a combination of considerations related to tritium pressure/inventory, compatibility and the high melting temperature of Flibe.

$\mathrm{SiC} / \mathrm{SiC}$ Composites

- $\quad \mathrm{SiC} / \mathrm{SiC}$ composites are at an early stage of development and still present a number of unresolved issues such as joining, hermeticity for He coolant and plasma, and cost that are not addressed here. 
- $\quad$ Projected high operating temperatures (to $-1000^{\circ} \mathrm{C}$ ) provide for high power conversion efficiency with He coolant.

- $\quad$ The upper temperature limits may be affected by Be multiplier and ceramic breeder temperature limits or by compatibility limits with liquid breeders.

- The reduction of thermal conductivity during irradiation poses a serious limitation to the surface heat load capability of $\mathrm{SiC} / \mathrm{SiC}$. This effect is more critical at temperatures of $500^{\circ} \mathrm{C}$ and below and will probably be exacerbated by the high $\mathrm{He}$ and $\mathrm{H}$ transmutation rates.

- The effects of high $\mathrm{He}$ and $\mathrm{H}$ transmutations on swelling and the mechanical properties are unresolved.

Refractory Alloys ( $\mathrm{Ta}, \mathrm{Nb}, \mathrm{Mo}, \mathrm{W})$

- Ta alloys are considered unacceptable based solely on neutronic properties.

- Key issues for $\mathrm{Nb}$-alloys relate to the minimum temperature for radiationinduced embrittlement (possibly $>500^{\circ} \mathrm{C}$ ) and the concern related to longterm activation. Compatibility issues are similar to those for vanadium alloys.

- $\quad$ Key issues for Mo alloys relate to the minimum temperature limit for radiation-induced embrittlement (estimated to be $>600^{\circ} \mathrm{C}$ ), welding and fabrication difficulties, and long-term activation. Issues related to oxidation and tritium containment for He-cooled systems remain a question.

- $\quad$ Key issues for W alloys are similar to those for Mo alloys except the minimum temperature for embrittlement is expected to be higher (possibly $>800^{\circ} \mathrm{C}$ ) and welding/fabrication is even more difficult. The relatively high transmutation rates to $\operatorname{Re}$ are also a concern. The oxidation/tritium issue for He coolant and operation of breeding materials at the high temperatures are major concerns.

\section{Conclusion}

This paper presents an assessment of the influence of key candidate structural materials properties on the performance limits for fusion first-wall/blanket applications. Key issues associated with interactions of the structural materials with the candidate coolant/breeder materials are addressed. The dominant uncertainties regarding the performance limits for the primary candidate first-wall/blanket structural materials relate to effects of fusion- 
relevant $\mathrm{He}$ and $\mathrm{H}$ transmutation rates on the structural materials properties. Of particular significance is the extension of the ITER structural materials design criteria to advanced structural materials and power system conditions. The new criteria indicate that significantly higher performance (wall load and high temperature) may be allowable for certain conditions than were projected based on older structural design criteria. 
References

[1] E.E. Bloom, J. Nucl. Mater. 258-263 (1998) 7-17.

[2] D.L. Smith et al., J. Nucl. Mater. 258-268 (1998) 65-73.

[3] K. Ioki et al., J. Nucl. Mater. 258-263 (1998) 74-84.

[4] M. Abdou, new High Power Density, High Availability concepts Based on the APEX Study, Fusion Engr. \& Design (in Press)

[5] L.L. Snead et al., J. Nucl. Mater. 233-237 (1996) 26-36.

[6] L.L. Snead et al., In-situ thermal conductivity measurement of silicon carbide in a fast neutron environment, J. Nucl. Mater. (in press).

[7] S. Majumdar and P. Smith, Fusion Engr. \& Design 41 (1998) 25-30.

[8] S. Majumdar, Structural Design criteria for high heat flux components, Fusion Engr. \& Design (in press).

[9] D.L. Smith et al., Fusion Engr. \& Design 41 (1998) 7-14.

[10] A. Hishinuma et al., J. Nucl. Mater. 258-263 (1998) 193-204. 
*The submitted manuscript has been created by the University of Chicago as Operator of Argonne National Laboratory ("Argonne") under contract No. W-31-109-ENG-38 with the U.S. Department of Energy. The U.S. Government retains for itself, and others acting on its behalf, a paid-up, nonexclusive, irrevocable worldwide license in said article to reproduce, prepare derivative works, distribute copies to the public, and perform publicly and display publicly, by or on behalf of the Government.

Work supported by the Office of Fusion Energy Sciences, U.S. Department of Energy, under Contract No. W-31-109-ENG-38. 
Table 1. Candidate First-Wall Materials for Fusion Systems

\begin{tabular}{lll}
\hline $\begin{array}{l}\text { Primary Candidate } \\
\text { Structural Materials }\end{array}$ & $\begin{array}{l}\text { Refractory Metals } \\
\text { Suggested for }\end{array}$ & $\begin{array}{l}\text { Free Surface } \\
\text { Liquid-Wall } \\
\text { High Performance }\end{array}$ \\
& Materials &
\end{tabular}

\begin{tabular}{lll}
$\begin{array}{l}\text { Ferritic Steels } \\
\text { Vanadium Alloys }\end{array}$ & $\begin{array}{l}\text { Tungsten Alloys } \\
\text { Tantalum Alloys } \\
\text { Molybdenum Alloy }\end{array}$ & $\begin{array}{l}\text { Lithium } \\
\mathrm{Li}_{2} \mathrm{BeF}_{4} \text { (Flibe) } \\
\mathrm{Sn25Li} \text { Alloy } \\
\text { Niobium Alloys }\end{array}$ \\
$\begin{array}{ll}\text { Copper Alloys * } \\
\text { Austenitic Steels * }\end{array}$ & & \\
& & \\
\hline
\end{tabular}

* Primarily for near-term devices 
Table 2. Neutronic Responses of First-Wall/Blanket Structural Materials*

\begin{tabular}{|c|c|c|c|c|c|}
\hline Alloy & $\begin{array}{c}\text { dpa** }^{* *} \\
\left(15 \mathrm{MWy} / \mathrm{m}^{2}\right)\end{array}$ & $\begin{array}{c}\text { He Transmut** } \\
\text { appm } \\
\left(15 \mathrm{MWy} / \mathrm{m}^{2}\right)\end{array}$ & $\begin{array}{l}\text { H Transmut** } \\
\text { appm } \\
\left(15 \mathrm{MWy} / \mathrm{m}^{2}\right)\end{array}$ & $\begin{array}{l}\text { Dose Rate } \text { Ra** }^{* *} \text { Sv/hr }\end{array}$ & $\begin{array}{c}\text { Decay Heat*** } \\
\text { W/kg }\end{array}$ \\
\hline Austenitic Steel & 170 & 2400 & 8550 & 4000 & 3 \\
\hline Ferritic Steel & 170 & 1800 & 7350 & 1000 & 1 \\
\hline Vanadium Alloy & 170 & 855 & 4050 & 0.3 & 0.005 \\
\hline SiC/SiC Comp & 135 & 19500 & 13350 & 0.0001 & 0.00003 \\
\hline Niobium Alloy & 95 & 495 & 1725 & 4000 & 4 \\
\hline Molybdenum Alloy & 95 & 525 & 5250 & 500 & 0.3 \\
\hline Tantalum Alloy & 51 & 45 & 135 & 1000000 & 1000 \\
\hline Tungsten Alloy & 45 & 51 & 135 & 1000 & 10 \\
\hline Copper & 210 & 1500 & 8700 & 2000 & 1 \\
\hline
\end{tabular}


Table 3. Calculated temperature gradient through first wall for surface heat fluxes of 1 and $2 \mathrm{MW} / \mathrm{m}^{2}$

STRUCTURAL $\quad \Delta \mathrm{T},{ }^{\circ} \mathrm{C}$

MATERIAL

$1 \mathrm{MW} / \mathrm{m}^{2}$

$2 \mathrm{MW} / \mathrm{m}^{2}$

Ferritic Steel

140

280

(4 mm wall)

Vanadium Alloys

120

240

(4 $\mathrm{m}$ wall)

$\mathrm{SiC} / \mathrm{SiC}$ (6 m wall)

$\begin{array}{lll}K_{t}=30 \mathrm{w} / \mathrm{m} \cdot \mathrm{K} & 200 & 400 \\ \mathrm{~K}_{\mathrm{t}}=20 \mathrm{w} / \mathrm{m} \cdot \mathrm{K} & 300 & 600 \\ \mathrm{~K}_{\mathrm{t}}=10 \mathrm{w} / \mathrm{m} \cdot \mathrm{K} & 600 & 1200\end{array}$




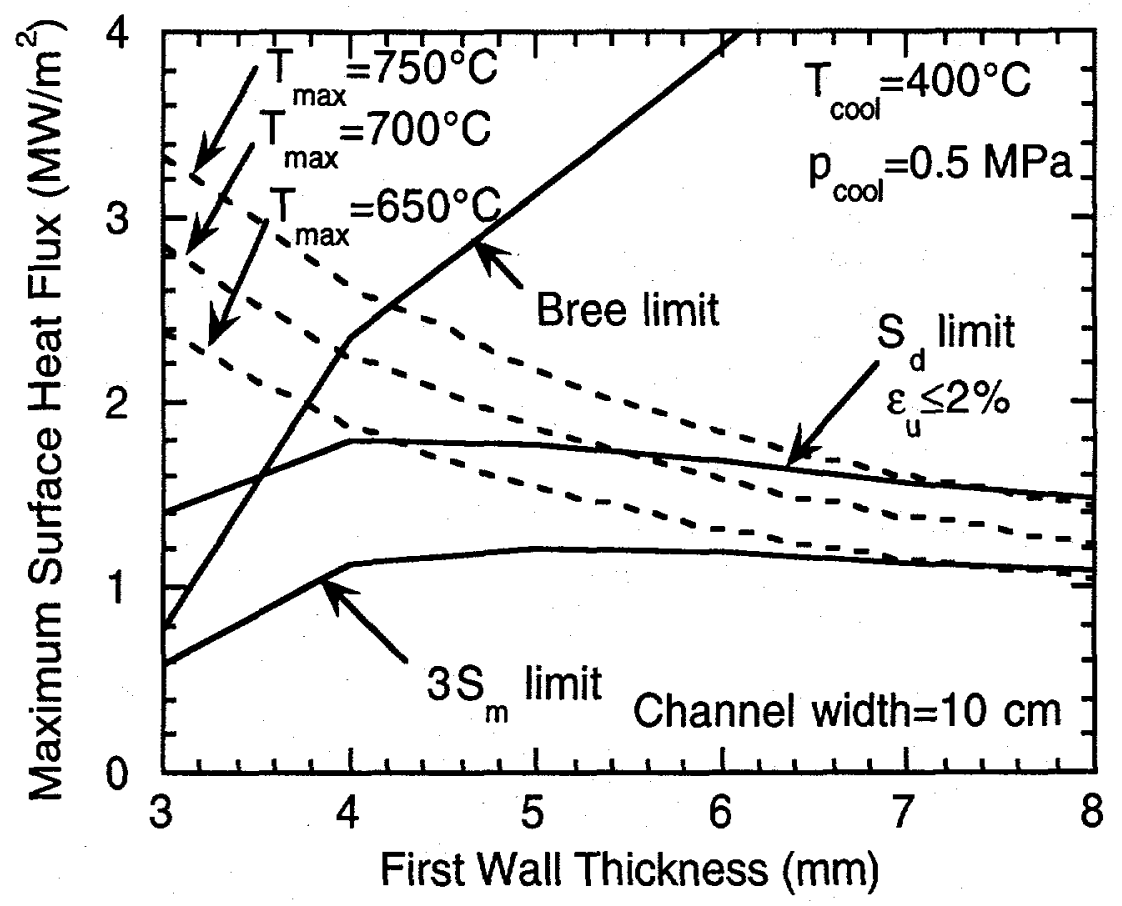

Fig. 1 Time independent maximum surface Heat Flux as a function of Wall Thickness for vanadium alloy structure 


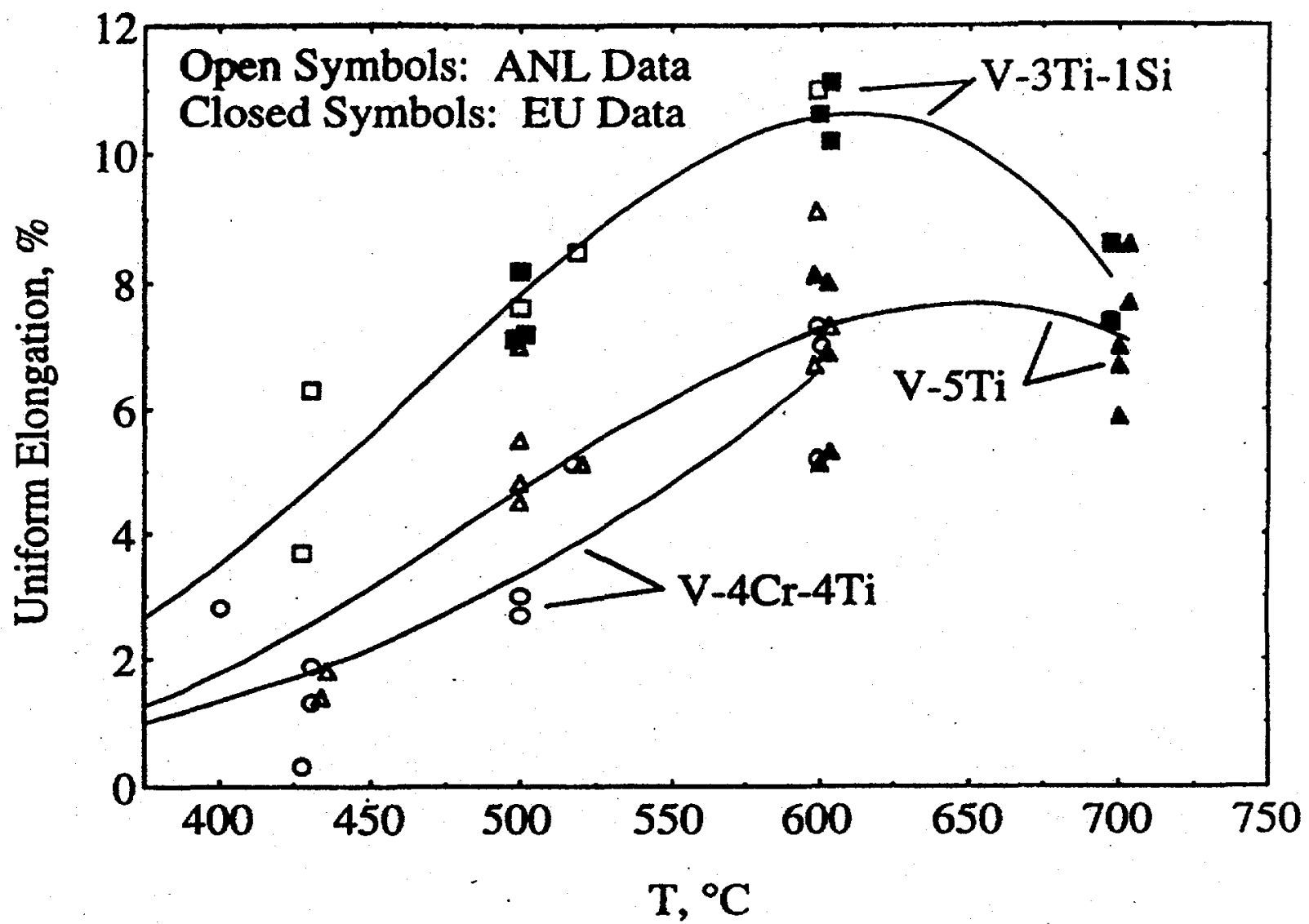

Fig. 2 Uniform elongation of irradiated (6-33 dpa) vanadium alloys compared to irradiated ( $36 \mathrm{dpa}) \mathrm{F} 82 \mathrm{H}$ (test temperature $\approx$ irradiation temperature). 


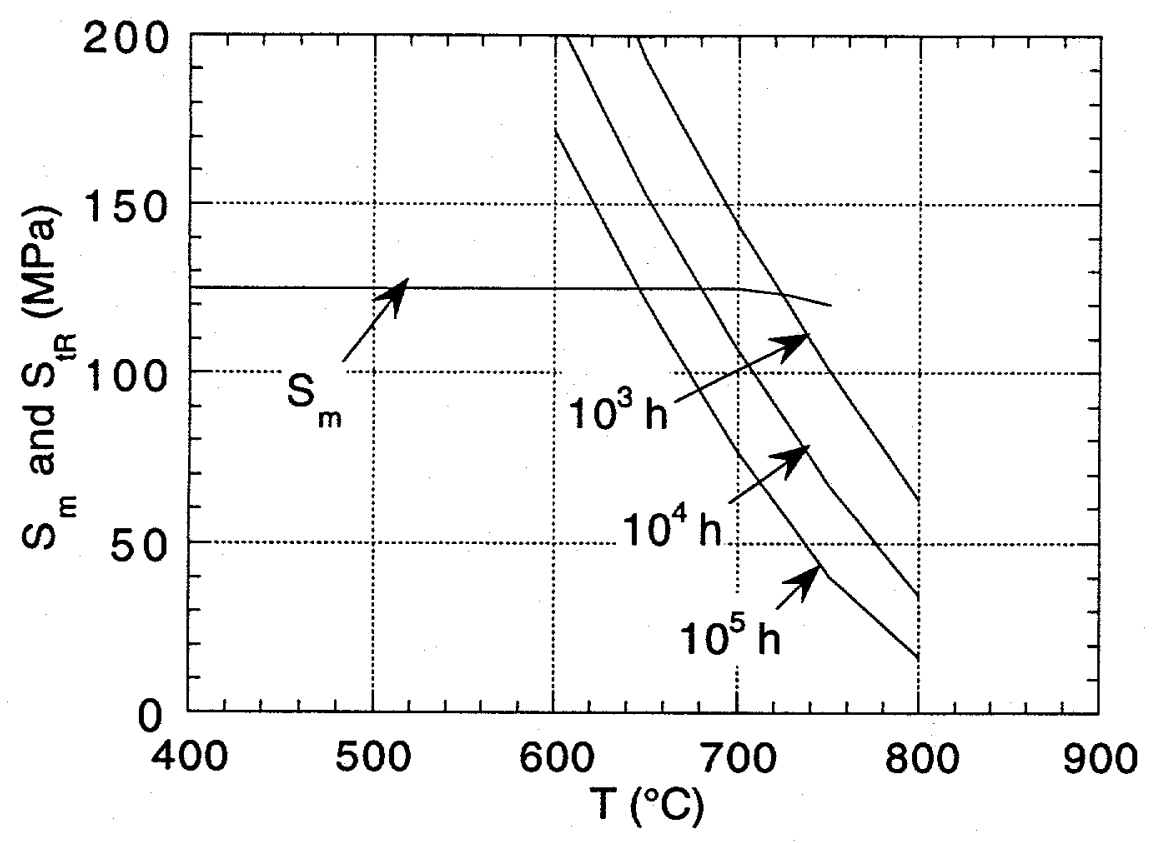

Fig. 3 Primary tensile and creep stress design limits as a function of temperature and time for a vanadium alloy structure 


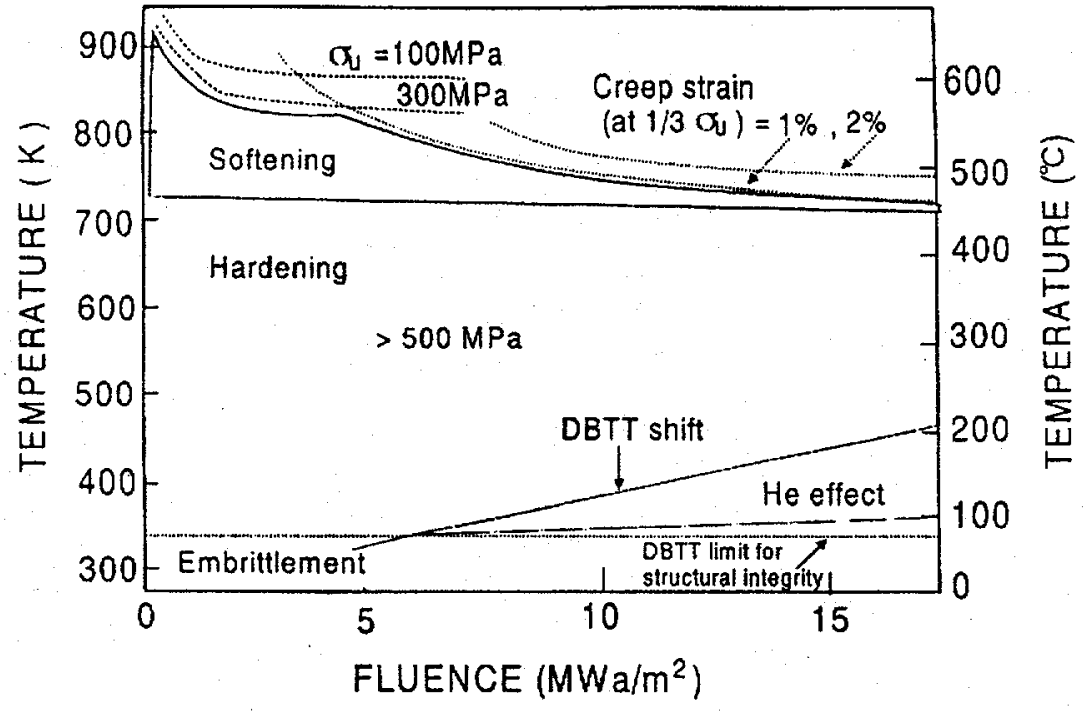

Fig. 4 Schematic design window for a tokamak-type fusion reactor with a ferritic steel first-wall structure (Hishinuma et al.) 
Table 4. Tritium Pressure in Breeder Systems ( $\triangle \mathrm{P}$ per Pass, $\mathrm{Pa})$

$$
\begin{array}{lcc}
-\mathrm{Li} & - & \sim 10^{13} \mathrm{~Pa} \\
-\mathrm{PbLi} & - & \sim 0.1 \mathrm{~Pa} \\
- \text { Flibe } & - & \sim 5 \mathrm{~Pa} \\
\text { - Li Ceramic } & \text { (He Purge) } \sim 5 \mathrm{~Pa}
\end{array}
$$


Table 5. Oxygen concentrations in He at 100 atm for oxidation of molybdenum and tungsten

\begin{tabular}{|c|c|c|}
\hline $\mathrm{Mo}_{2}$ & : & $10^{-8} \mathrm{ppm} \underline{0}$ at $700^{\circ} \mathrm{C}$ \\
\hline $\mathrm{N}_{2}$ & & $10^{-7} \mathrm{ppm} \underline{0}$ at $700^{\circ} \mathrm{C}$ \\
\hline
\end{tabular}




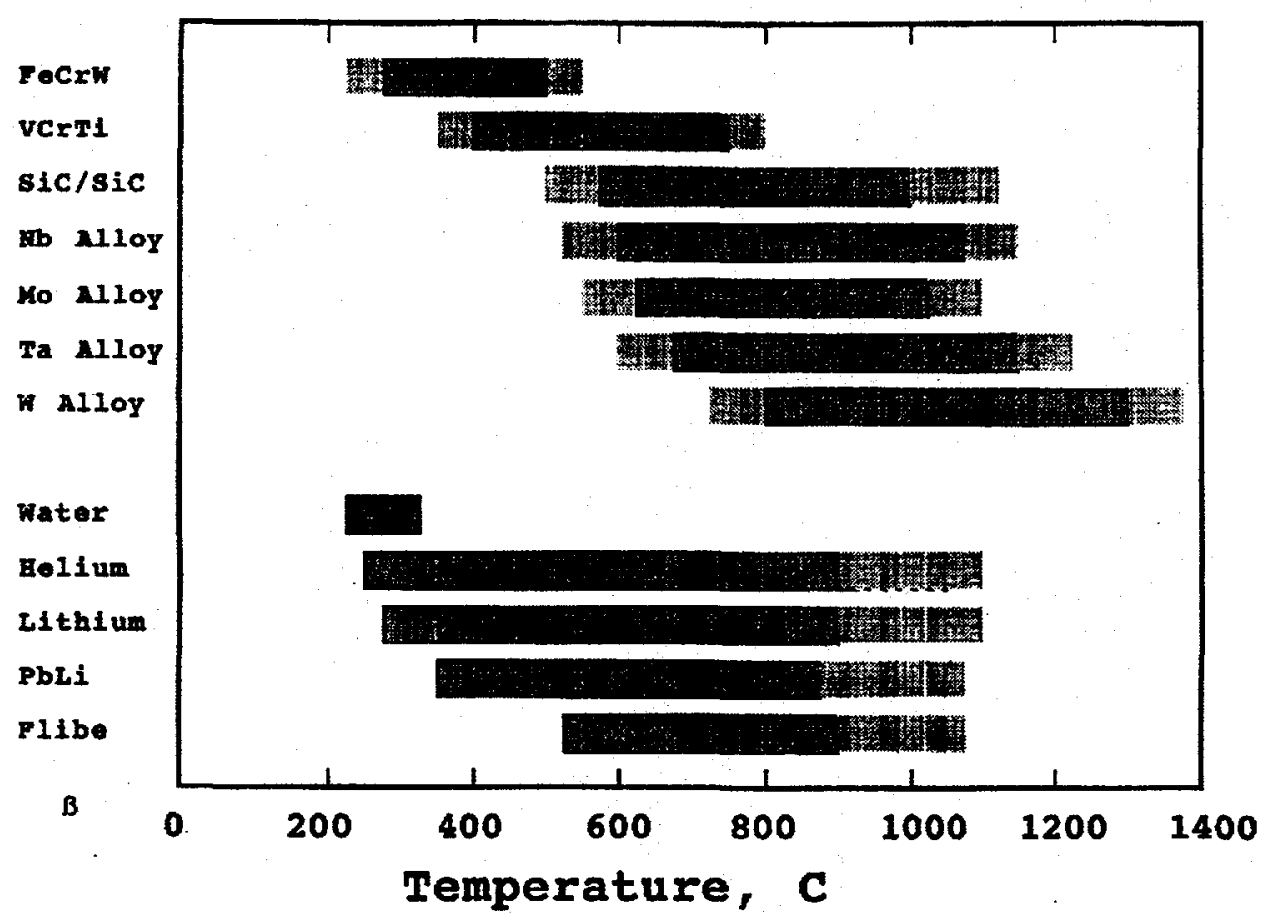

Fig. 5 Estimated operating temperature ranges for candidate structures and coolants 